\title{
Efeito da adição de suco de maracujá e tempo de cozimento sobre a qualidade de doces do albedo de maracujá em calda
}

\author{
Effect of the addition of passion fruit juice and cooking time on the quality of passion fruit albedo preserves
}

\author{
Luisa Pereira FIGUEIREDO ${ }^{1}$, Wanderson Alexandre VALENTE ${ }^{1}$, Marali Vilela DIAS ${ }^{1}$, Soraia Vilela BORGES ${ }^{1 \star}$, \\ Patrícia Aparecida Pimenta PEREIRA ${ }^{1}$, Anirene Galvão Tavares PEREIRA ${ }^{1}$, Paulo Roberto CLEMENTE ${ }^{1}$
}

\begin{abstract}
Resumo
O Brasil gera toneladas de resíduos de cascas e sementes de maracujá amarelo que podem ser aproveitados na alimentação humana. Os objetivos deste trabalho foram determinar os efeitos dos parâmetros do processo (volume do suco de maracujá empregado e tempo de cozimento dos albedos) sobre as propriedades físico-químicas ( $\mathrm{pH}$, sólidos solúveis, acidez titulável e açúcares totais) de doces em calda elaborados com a casca do maracujá, bem como sua aceitação sensorial pelos consumidores, visando o reaproveitamento dos resíduos gerados na indústria de alimentos. Utilizou-se um planejamento fatorial $2^{2}$ completo para avaliação dos parâmetros e respostas. Avaliou-se a aceitação sensorial dos doces, utilizando-se escala hedônica de 9 pontos, e intenção de compra, usando-se escala de 5 pontos. Valores mais baixos de $\mathrm{pH}$ foram alcançados em volumes de suco e tempo de cozimento mais altos, tanto para o albedo como para a calda do doce. Maiores valores de sólidos solúveis no albedo foram encontrados em tempos de cozimento altos e em menores volumes de suco empregado. Resultados globais indicaram como condições adequadas, ao processamento do albedo de maracujá em calda, tempo de cozimento superior a 10 minutos e concentração mais elevada de suco de maracujá.

Palavras-chave: Passiflora edulis f. flavicarpa; frutas; processamento; análises físico-químicas; análise sensorial.
\end{abstract}

\begin{abstract}
Brazil produces tons of yellow passion fruit skin and seed residues that could be used for human consumption. The objective of this work was to determine the effects of the process parameters (volume of passion fruit juice used and cooking time of the albedos), on the physicochemical properties ( $\mathrm{pH}$, soluble solids, titratable acidity and total sugars) of compote prepared with passion fruit skin, and the sensory acceptance by consumers aiming to use the residues produced by food industries. A complete $2^{2}$ factorial design was used to evaluate the parameters and responses. The sensory acceptance of the preserves was evaluated using a 9-point hedonic scale and buying intention using a 5-point scale. Lower $\mathrm{pH}$ values were obtained using larger volumes of juice and longer cooking times, both for the albedo and the preserves. For the albedo, higher values for soluble solids were found with longer cooking times and smaller volumes of juice. The overall results indicated a cooking time longer than 10 minutes and a larger volume of passion fruit juice as the most adequate processing conditions.

Keywords: Passiflora edulis f. flavicarpa; fruits; processing; physicochemical analyses; sensory analyses.
\end{abstract}

\section{Introdução}

O maracujá é uma cultura típica de países de clima tropical, responsáveis por cerca de $90 \%$ da produção mundial. O Brasil é, atualmente, o maior produtor (e o maior consumidor) seguido do Peru, Venezuela, África do Sul, Sri Lanka e Austrália (SANDI et al.., 2003). O maracujá azedo (Passiflora edulis $f$. flavicarpa) representa cerca de $97 \%$ da área plantada e do volume comercializado em todo o País (BRIGNANI NETO, 2002). Estima-se que mais de $60 \%$ da produção brasileira de maracujá azedo seja destinada ao consumo in natura, através de sacolões, feiras, supermercados, etc. O restante é destinado às indústrias de processamento, sendo o suco o principal produto.

A utilização do maracujá para a produção de suco resulta em grande quantidade de resíduos, uma vez que cerca de $60-70 \%$ do peso total do fruto é representado pela casca (albedo) e sementes, as quais apresentam propriedades funcionais e podem ser utilizadas para o desenvolvimento de novos produtos (CÓRDOVA et al., 2005).

A fome e o desperdício de alimentos são dois grandes problemas que o Brasil enfrenta, constituindo-se em um dos paradoxos do País, pois o Brasil é um dos maiores exportadores de produtos agrícolas do mundo, produz 140 milhões de toneladas de alimentos por ano, e, ao mesmo tempo, existem milhões de excluídos sem acesso ao alimento em quantidade e/ou qualidade (GONDIM et al., 2005).

Por ser constituído basicamente por carboidratos, proteínas e pectinas, o albedo de maracujá possibilita o seu aproveitamento para a elaboração de doces em calda, conforme prévio trabalho desenvolvido por Oliveira et al. (2002), os quais adicionaram condimentos à calda e obtiveram excelente aceitabilidade do

Recebido para publicação em 24/1/2008

Aceito para publicação em 4/1/2009 (003172)

Departamento de Ciência dos Alimentos, Universidade Federal de Lavras - UFLA, Campus Universitário, CP 3037, CEP 37200-000, Lavras - MG, Brasil,

E-mails:lupefi@bol.com.br; wavalente@bol.com.br; maralivdias@hotmail.com; sborges@ufla.br; pattyap2001@yahoo.com.br; anigtp04@hotmail.com; clemente@ufla.br

${ }^{*}$ A quem a correspondência deve ser enviada 
doce por parte de crianças e adultos, com índices de aceitação de 94,2 e $85,2 \%$, respectivamente. Adicionalmente este processo proporciona períodos longos de conservação, garantindo um maior valor agregado ao produto.

A qualidade e aceitabilidade de produtos alimentícios encontram-se intimamente associadas às propriedades físico-químicas e sensoriais, sendo dependentes do tipo de tratamento e dos parâmetros do processo aos quais as frutas são submetidas. Dentre os muitos fatores que interferem na qualidade de doces em calda, podemos destacar a acidez e tempo de cozimento (OLIVEIRA et al., 2002; SATO; CUNHA, 2005). Entretanto, segundo Modesta et al. (2005), o sabor do maracujá é extremamente sensível ao tratamento térmico.

Os objetivos deste trabalho foram determinar os efeitos dos parâmetros do processo (volume do suco de maracujá empregado na formulação e tempo de cozimento dos albedos na calda) sobre as propriedades físico-químicas, de formulações de doces em calda elaborados com a casca do maracujá, correlacionando-as com a aceitação sensorial pelos consumidores, visando incentivar o reaproveitamento dos resíduos gerados na indústria de alimentos.

\section{Material e métodos}

\subsection{Materiais}

Foram utilizados albedos obtidos dos frutos do maracujá amarelo (Passiflora edulis forma Flavicarpa) no estádio de maturação maduro, com coloração da casca amarela, fornecidos pela FRUTILAVRAS (Associação dos Fruticultores de Lavras), suco da própria fruta e açúcar tipo refinado, marca UNIÃO.

\subsection{Métodos}

\section{Planejamento experimental}

Foi utilizado um delineamento experimental do tipo fatorial completo, com 2 fatores (volume de suco de maracujá empregado na formulação e tempo de cozimento dos albedos na calda), 2 níveis e três repetições no ponto central, para avaliação do erro experimental (BARROS NETO et al., 1995), resultando em 7 tratamentos, conforme mostra a Tabela 1.

O planejamento objetivou avaliar a influência de variáveis independentes ou fatores sobre as variáveis dependentes ou

Tabela 1. Planejamento fatorial de dois níveis com ponto central.

\begin{tabular}{ccccc}
\hline Tratamentos & $\begin{array}{c}\text { Variável } \\
\text { codificada } \\
\mathrm{x} 1\end{array}$ & $\begin{array}{c}\text { Variável } \\
\text { real VS } \\
(\mathrm{mL})\end{array}$ & $\begin{array}{c}\text { Variável } \\
\text { codificada } \\
\mathrm{x} 2\end{array}$ & $\begin{array}{c}\text { Variável } \\
\text { real TC } \\
\text { (minutos) }\end{array}$ \\
\hline 1 & +1 & 90 & +1 & 20 \\
2 & -1 & 50 & +1 & 20 \\
3 & +1 & 90 & -1 & 10 \\
4 & -1 & 50 & -1 & 10 \\
5 & 0 & 70 & 0 & 15 \\
6 & 0 & 70 & 0 & 15 \\
7 & 0 & 70 & 0 & 15 \\
\hline
\end{tabular}

${ }^{\star} \mathrm{VS}=$ volume de suco; $\mathrm{e}$ TC $=$ tempo de cozimento. respostas (físico-químicas). A análise de variância (ANOVA), determinação dos coeficientes de regressão, avaliação dos efeitos ao nível de 5\% de probabilidade e geração das superfícies de resposta foram realizadas pelo programa STATISTICA versão 5.0. Para os fatores (parâmetros) cujos efeitos foram significativos sobre as respostas, foi ajustado um modelo multilinear, por regressão multilinear.

\section{Processamento dos doces}

Os maracujás recebidos foram lavados, sanitizados com água clorada a 200 ppm, cortados manualmente e despolpados. As cascas foram cortadas verticalmente em 4 partes, as quais possuíam espessura do albedo entre 9-12 mm (medidas com paquímetro), e submetidas à cocção sob pressão por 5 minutos em um recipiente com água potável em quantidade suficiente para cobri-las. Posteriormente se procedeu à retirada do flavedo (película amarela externa), com auxílio de uma colher.

A calda, para posterior cozimento dos albedos, foi previamente preparada na proporção $(\mathrm{p} / \mathrm{v})$ de açúcar/água de 1:2 e fervida por aproximadamente 5 minutos, em tacho de aço inoxidável, obtendo-se uma concentração de sólidos solúveis de 40 Brix, medido em refratômetro. Em seguida adicionou-se o volume de suco de maracujá concentrado e os albedos foram cozidos, conforme planejamento experimental descrito na Tabela 1. A cocção procedeu-se em tacho aberto de aço inoxidável com capacidade para $5 \mathrm{~L}$, com agitação manual, proporção (p/v) albedo/calda de 1:2. O envase foi feito a quente em embalagens de vidro com capacidade para $250 \mathrm{~g}$, previamente esterilizadas por imersão em água em ebulição por 15 minutos, fechadas com tampa de metal, imediatamente resfriadas em água corrente e armazenadas à temperatura ambiente por 21 dias, tempo previamente determinado para atingir o equilíbrio em pH e brix de calda e albedo (FIGUEIREDO et al., 2007).

\section{Análises físico-químicas}

As análises físico-químicas foram realizadas em triplicatas no albedo e na calda dos doces em calda elaborados com o albedo do maracujá, determinadas segundo técnica da AOAC (2000). $\mathrm{O}$ pH foi determinado em pHmetro digital Tec-3MP (Tecnal); o teor de sólidos solúveis (SS) foi determinado utilizando-se um refratômetro digital ATAGO modelo PR-100; a acidez titulável (AT) foi determinada por titulometria com $\mathrm{NaOH}$ $0,1 \mathrm{~N}$ em presença de fenolftaleína e açúcares totais (ACT) por titulometria com o reagente de antrona. Os resultados foram apresentados através de médias, com os respectivos desvios padrões, correspondentes a três triplicatas e expressos em base úmida.

\section{Avaliação sensorial}

A avaliação sensorial foi realizada por uma equipe de 30 julgadores não treinados, recrutados entre funcionários e estudantes da Universidade Federal de Lavras. A equipe abrangeu indivíduos de ambos os sexos representativos do público consumidor. Foram servidos 5 doces (numerados de 1 a 5) referentes aos respectivos tratamentos do planejamento experimental, sendo o doce 5 representado pela aleatorização 
dos tratamentos 5, 6 e 7. Os doces foram servidos à temperatura ambiente em sala de avaliação sensorial, com cabines individuais, dispostos em recipientes descartáveis codificados com números aleatórios de três dígitos. $\mathrm{O}$ experimento foi instalado em delineamento de blocos completos balanceados, conforme Moraes (1993). Escalas hedônicas estruturadas de nove pontos (abrangendo de "gostei extremamente" a "desgostei extremamente") foram utilizadas no teste de aceitação do doce do albedo do maracujá em calda. A intenção de compra foi avaliada mediante escala estruturada (abrangendo de "certamente compraria" a "certamente não compraria"). Os resultados da avaliação sensorial para cada atributo foram analisados por Análise de Variância (ANOVA) e, para os resultados significativos, as médias foram comparadas pelo teste de Tukey (5\% de significância), utilizando-se o programa SISVAR $^{\oplus}$ (FERREIRA, 2000). Realizou-se ainda a análise de frequência para cada formulação em relação aos atributos para permitir melhor distinção entre as formulações.

\section{Resultados e discussão}

\subsection{Caracterização físico-química}

Nas Tabelas 2 e 3, são apresentados os valores das médias e desvios padrões das análises físico-químicas para o albedo e para a calda, respectivamente, do doce em calda dos albedos do maracujá.

Machado et al. (2003) encontraram valores de $\mathrm{pH}$, acidez titulável e açúcares totais iguais a 4,52, 0,20 e 1,35\%, respectivamente, para o albedo do maracujá in natura. Com o processamento na calda, incorporação do suco e cozimento, o pH foi reduzido e os teores de acidez e açúcares elevados. Sato, Sanjinez-Argandona e Cunha (2004) também verificaram aumento no teor de açúcares totais em goiabas em calda industrializadas, quando comparadas com goiabas in natura. Estes resultados mostram que o processamento de frutas em calda leva a uma redução da umidade (concentração), com consequente aumento no teor de açúcares do fruto, devido ao efeito da pressão osmótica da calda de cobertura. De forma semelhante aos doces de maracujá em calda, Patri, Nogueira e Dias (2002) verificaram redução do $\mathrm{pH}$ de carambolas doces e ácidas submetidas ao processamento para a produção de doces em calda, quando comparadas com a fruta in natura.

Observa-se que as médias dos valores encontrados para acidez e teor de sólidos solúveis para a calda, em geral, foram superiores quando comparados com Freitas e Jerônimo (2005), iguais a $0,22 \%$ e $43,22{ }^{\circ}$ Brix, respectivamente, para doce de tomate em calda, o que caracteriza o doce em calda do albedo do maracujá como um produto de sabor mais ácido ocasionado pela adição de suco de maracujá e também mais doce resultante de uma maior concentração da calda.

Maiores valores de sólidos solúveis e açúcares totais são encontrados na calda quando comparadas com os albedos, devido, provavelmente, à baixa permeabilidade da parede celular dos açúcares, conforme resultados previamente constatados para produção de goiaba em calda (SATO; CUNHA, 2005), e ao processo de evaporação, que eleva a concentração da calda.

A partir dos resultados mostrados nas Tabelas 2 e 3, foram avaliados sobre cada resposta os efeitos das variáveis codificadas $\mathrm{x} 1 \mathrm{e} \mathrm{x} 2$, referentes aos fatores volume de suco empregado na formulação e tempo de cozimento dos albedos na calda, respectivamente, os quais são apresentados nas Tabelas 4 e 5 .

Observa-se que o volume de suco empregado e o tempo de cozimento dos albedos na calda são fatores significativos na determinação do $\mathrm{pH}$ e sólidos solúveis do albedo e do $\mathrm{pH}$ da calda. O tempo de cozimento afetou significativamente todos

Tabela 2. Média e desvio padrão das análises físico-químicas do albedo do doce de maracujá em calda.

\begin{tabular}{ccccc}
\hline Ensaios & $\mathrm{pH}$ & Sólidos solúveis $\left({ }^{\circ}\right.$ Brix $)$ & Acidez titulável $\left(\mathrm{g}\right.$ ác.cítrico. $\left.100 \mathrm{~g}^{-1}\right)$ & ${\text { Açúcares totais }\left(\mathrm{g} \text { glicose. } 100 \mathrm{~g}^{-1}\right)}$ \\
\hline 1 & $3,08 \pm 0,01$ & $41,00 \pm 0,00$ & $0,35 \pm 0,00$ & $66,96 \pm 2,19$ \\
2 & $3,23 \pm 0,01$ & $46,67 \pm 0,00$ & $0,27 \pm 0,07$ & $66,30 \pm 8,13$ \\
3 & $3,15 \pm 0,01$ & $35,00 \pm 0,00$ & $0,31 \pm 0,07$ & $48,13 \pm 2,30$ \\
4 & $3,34 \pm 0,01$ & $37,00 \pm 0,00$ & $0,23 \pm 0,12$ & $60,03 \pm 0,67$ \\
5 & $3,23 \pm 0,01$ & $39,00 \pm 0,00$ & $0,27 \pm 0,07$ & $67,46 \pm 0,02$ \\
6 & $3,25 \pm 0,01$ & $38,00 \pm 0,00$ & $0,27 \pm 0,07$ & $58,40 \pm 3,12$ \\
7 & $3,24 \pm 0,01$ & $39,67 \pm 0,00$ & $0,35 \pm 0,00$ & $65,70 \pm 4,90$ \\
\hline
\end{tabular}

Tabela 3. Média e desvio padrão das análises físico-químicas da calda do doce de maracujá em calda.

\begin{tabular}{ccccc}
\hline Ensaios & $\mathrm{pH}$ & Sólidos solúveis $\left({ }^{\circ}\right.$ Brix $)$ & Acidez titulável $\left(\mathrm{g}\right.$ ác.cítrico. $\left.100 \mathrm{~g}^{-1}\right)$ & Açúcares totais $\left(\mathrm{g}\right.$ glicose. $\left.100 \mathrm{~g}^{-1}\right)$ \\
\hline 1 & $3,18 \pm 0,01$ & $52,67 \pm 0,00$ & $0,46 \pm 0,00$ & $81,33 \pm 10,91$ \\
2 & $3,33 \pm 0,03$ & $61,00 \pm 0,00$ & $0,39 \pm 0,06$ & $82,01 \pm 1,46$ \\
3 & $3,25 \pm 0,01$ & $41,00 \pm 0,00$ & $0,35 \pm 0,00$ & $65,42 \pm 3,29$ \\
4 & $3,42 \pm 0,03$ & $42,67 \pm 0,00$ & $0,27 \pm 0,07$ & $52,36 \pm 0,25$ \\
5 & $3,32 \pm 0,01$ & $47,00 \pm 0,00$ & $0,31 \pm 0,07$ & $66,61 \pm 1,16$ \\
6 & $3,31 \pm 0,01$ & $48,67 \pm 0,00$ & $0,31 \pm 0,07$ & $66,14 \pm 9,53$ \\
7 & $3,31 \pm 0,01$ & $45,67 \pm 0,00$ & $0,23 \pm 0,00$ & $70,79 \pm 12,12$ \\
\hline
\end{tabular}


Figueiredo et al.

Tabela 4. Avaliação dos efeitos dos fatores sobre as determinações físico-químicas do albedo.

\begin{tabular}{|c|c|c|c|c|}
\hline Fator & $\mathrm{pH}$ & Sólidos solúveis ( $\left.{ }^{\circ} \mathrm{Brix}\right)$ & Acidez titulável (g ác. cítrico. $100 \mathrm{~g}^{-1}$ ) & Açúcares totais (g de glicose. $\left.100 \mathrm{~g}^{-1}\right)$ \\
\hline Média & 3,22 & 39,47 & 0,29 & 60,43 \\
\hline $\mathrm{x} 1$ & $-0,17^{\star}$ & $-3,83^{*}$ & $0,08^{\mathrm{ns}}$ & $-10,62^{\text {ns }}$ \\
\hline $\mathrm{x} 2$ & $-0,09^{*}$ & $7,83^{*}$ & $0,04^{\text {ns }}$ & $7,55^{\mathrm{ns}}$ \\
\hline x1 X x2 & $0,02^{\text {ns }}$ & $-1,83^{\mathrm{ns}}$ & $0,00^{\text {ns }}$ & $1,28^{\mathrm{ns}}$ \\
\hline
\end{tabular}

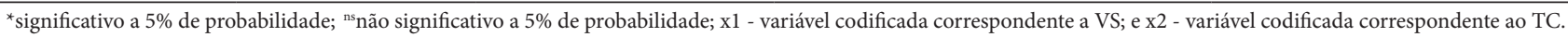

Tabela 5. Avaliação dos efeitos dos fatores sobre as determinações físico-químicas da calda.

\begin{tabular}{|c|c|c|c|c|}
\hline Fator & $\mathrm{pH}$ & Sólidos solúveis ( ${ }^{\circ}$ Brix) & Acidez titulável ( $\mathrm{g}$ ác. cítrico. $100 \mathrm{~g}^{-1}$ ) & Açúcares totais ( $\mathrm{g}$ de glicose. $\left.100 \mathrm{~g}^{-1}\right)$ \\
\hline Média & 3,30 & 48,38 & 0,33 & 69,24 \\
\hline $\mathrm{x} 1$ & $-0,16^{*}$ & $-5,00^{\text {ns }}$ & $0,07^{\mathrm{ns}}$ & $6,19^{\text {ns }}$ \\
\hline $\mathrm{x} 2$ & $-0,08^{\star}$ & $15,00^{*}$ & $0,11^{\mathrm{ns}}$ & $22,78^{*}$ \\
\hline $\mathrm{x} 1 \mathrm{X} \times 2$ & $0,01^{\mathrm{ns}}$ & $-3,33^{\mathrm{ns}}$ & $-0,005^{\mathrm{ns}}$ & $-6,87^{\mathrm{ns}}$ \\
\hline
\end{tabular}

${ }^{\star}$ Significativo a $5 \%$ de probabilidade; ${ }^{\text {ns }}$ não significativo a $5 \%$ de probabilidade; x1 - variável codificada correspondente a VS; e x2 - variável codificada correspondente ao TC.

os parâmetros físico-químicos analisados para a calda, com exceção apenas para acidez titulável.

Temperaturas elevadas aliadas ao tempo do processo promovem redução da resistência à transferência de massa na superfície do albedo, pois o calor altera a estrutura da parede celular, promovendo maior perda de água e maior ganho de açúcares (TONON; BARONI; HUBINGER, 2006) nos albedos. Estas alterações são devidas ao processo osmótico que é estabelecido em tais processos. Devido à diferença de concentração entre o agente osmótico (açúcar da calda) e a fruta, são criados dois fluxos simultâneos em contracorrente através das paredes celulares: um da água que sai da fruta para a solução e o outro de soluto da solução para a fruta (LIMA; BRUNO, 2006). Sato e Cunha (2005), avaliando o processamento de goiabas em calda, observaram uma perda de água maior que o ganho de açúcares na fruta em decorrência da maior facilidade de difusão de moléculas menores através da membrana, o que pode ser comprovado nos doces em calda do albedo do maracujá pelo fato do tempo de cozimento dos albedos ter afetado significativamente o teor de sólidos solúveis e não ter afetado o teor de açúcares totais no albedo, enfatizando uma maior perda de água do que ganho de açúcares.

Para visualizar e discutir melhor os efeitos dos fatores, modelos foram aplicados e superfícies foram geradas para as respostas em que ambos os fatores foram significativos.

As Equações 1 e 2 descrevem o pH em função das variáveis codificadas $\mathrm{x} 1$ e $\mathrm{x} 2$ para o albedo e calda, respectivamente, cujos coeficientes de correlação $\left(R^{2}\right)$ foram 0,93 e 0,98 , mostrando que este modelo ajustou-se bem aos dados experimentais, permitindo a geração das superfícies de resposta.

$\mathrm{pH}=3,22-0,08 \times 1-0,04 \times 2$

$\mathrm{pH}=3,30-0,08 \times 1-0,04 \times 2$

Observa-se pelas Figuras 1 e 2 que valores mais baixos de $\mathrm{pH}$, previstos pelo modelo, foram alcançados em volumes de suco e tempo de cozimento mais altos, tanto para o albedo como para a calda do doce.

Nos albedos, tempos de cozimento altos associados a temperaturas elevadas aumentam as chances de hidrólise da pectina (SOARES JUNIOR; MAIA; NELSON, 2003), resultando, segundo Oliveira et al. (2006), em um aumento no teor de ácidos em decorrência da liberação de ácido galacturônico, com consequente redução do $\mathrm{pH}$.

Machado et al. (2003) encontraram valores de $\mathrm{pH}$ para o albedo e suco de maracujá in natura iguais a 4,52 e 3,03, respectivamente, o que caracteriza o suco de maracujá com acentuada acidez quando comparado ao albedo. Desta forma, maiores volumes de suco de maracujá empregados na calda na elaboração dos doces, aliados a elevados tempos de cozimento, que provocam sua concentração, resultam em valores mais baixos de $\mathrm{pH}$ da calda. Ao mesmo tempo haverá uma grande impregnação de calda na superfície do albedo, por esta apresentar-se altamente viscosa (TONON; BARONI; HUBINGER, 2006), em função do elevado tempo de cozimento, resultando, de forma semelhante à calda, na redução do $\mathrm{pH}$ do albedo.

Os valores de $\mathrm{pH}$ encontrados para o albedo e calda demonstram que o processo de acidificação foi suficiente, pois, após o equilíbrio osmótico, os valores finais de $\mathrm{pH}$ não ultrapassaram 3,5 , sendo portanto menores que 4,5 , para que, segundo Godoy et al. (2005), garantam boa segurança quanto ao desenvolvimento de microrganismos. Os valores de $\mathrm{pH}$ da calda foram mais ácidos quando comparados com o de Freitas e Jerônimo (2005), igual a 4,08, para caldas do doce de tomate em calda; com o de Godoy et al. (2005), igual a 4,35, para caldas das compotas de albedos cítricos; e com o de Oliveira et al. (2002), igual a 4,0, para caldas de doce de casca de maracujá.

A Equação 3 descreve o teor de sólidos solúveis em função das variáveis codificadas x1 e x2 para o albedo, cujo coeficiente de correlação $\left(R^{2}\right)$ foi 0,96 , mostrando que este modelo ajustouse bem aos dados experimentais, permitindo a geração das superfícies de resposta. 


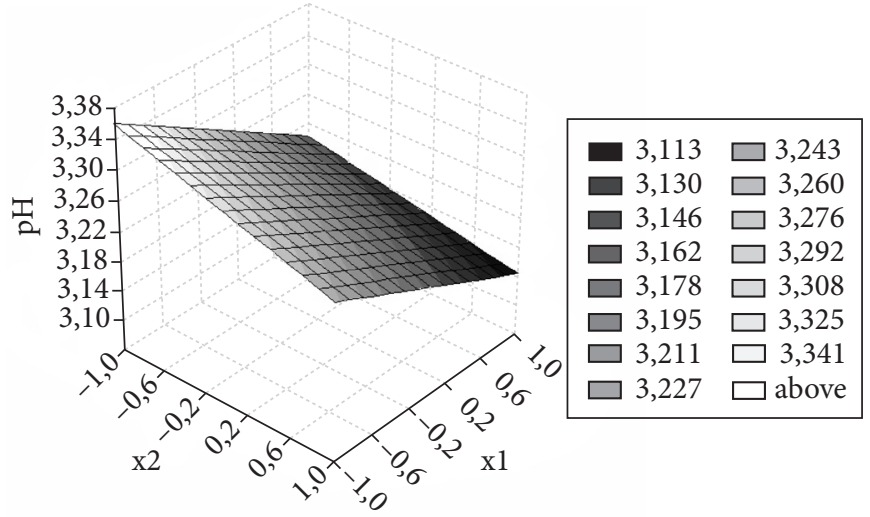

Figura 1. Variação do $\mathrm{pH}$ do albedo em função dos fatores avaliados.

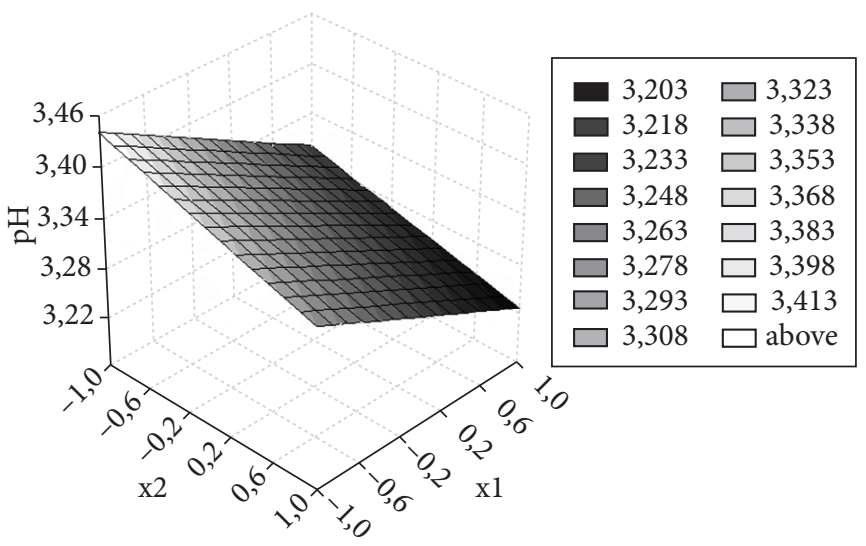

Figura 2. Variação do pH da calda em função dos fatores avaliados.

$\mathrm{SS}=39,47-1,92 \times 1+3,92 \times 2$

Observa-se na Figura 3 que maiores valores de sólidos solúveis (SS) no albedo são encontrados em tempos de cozimento maiores e em menores volumes de suco empregados na elaboração dos doces.

Tais resultados possivelmente se baseiam no fato de maiores tempos de cozimento associados à temperatura elevada proporcionarem uma maior saída de água dos albedos, com consequente ganho de açúcares, devido ao possível inchaço e plasticização sofridos pela membrana celular, que acarretam um aumento de sua permeabilidade (TONON; BARONI; HUBINGER, 2006), ocasionando aumento no teor de sólidos solúveis no albedo. Tais fatos, aliados a um menor volume de suco adicionado, evidenciam ainda mais o aumento no teor de sólidos solúveis no albedo, por obtermos uma calda mais concentrada, intensificando o processo osmótico (GOMES; CEREDA; VILPOUX, 2007).

Sato e Cunha (2005), em goiabas em calda, observaram que a maior transferência de massa ocorre nos 30 primeiros minutos do processo, proporcionando queda brusca nos

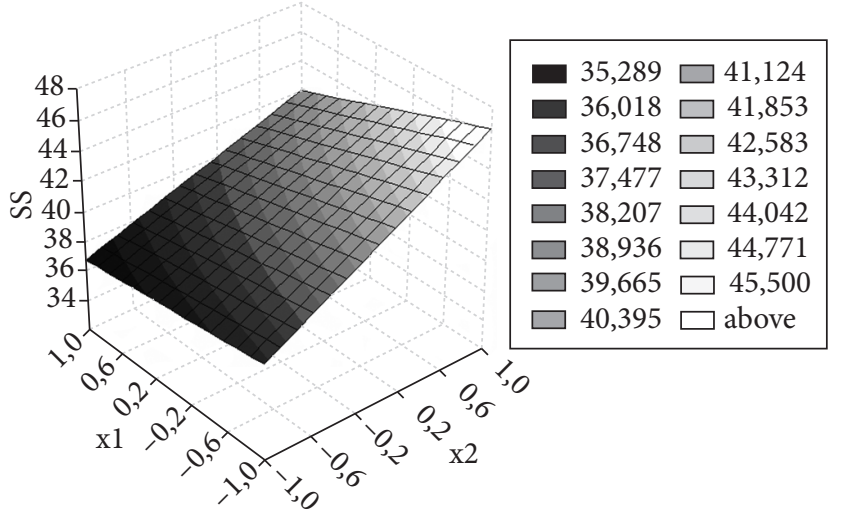

Figura 3. Variação do teor de sólidos solúveis do albedo em função dos fatores avaliados.

valores de umidade e um incremento mais acentuado no teor de açúcares.

A média dos valores de sólidos solúveis dos albedos dos doces em calda da casca do maracujá foi igual a 39,47 ${ }^{\circ} \mathrm{Brix}$, apresentando resultados semelhantes aos encontrados por Godoy et al. (2005) para doces em calda de diferentes albedos cítricos.

\subsection{Análise sensorial}

Os resultados da análise sensorial são apresentados na Tabela 6. Foram significativos $(\mathrm{p} \leq 0,05)$ os efeitos das médias das diferentes formulações dos doces nos diversos atributos sensoriais exceto para o atributo sabor.

O doce 4 apresentou diferença significativa em relação aos demais quanto aos atributos aparência, textura e cor, embora não tenha diferido do doce 3. Tal doce apresentou uma coloração mais clara, conforme observação feita pelos julgadores, ocasionada possivelmente em consequência de um menor volume de suco de maracujá empregado, associado a uma menor concentração da calda decorrente do reduzido tempo de cozimento do doce. Menores tempos de processamento podem ter comprometido a aceitação do doce 4, por este apresentar uma textura mais firme, devido possivelmente a uma menor degradação da estrutura celular. É interessante observar que o doce 3 permaneceu em cozimento pelo mesmo tempo que o 4, mostrando que o tempo de cozimento reduzido influenciou diretamente na avaliação dos provadores quanto aos atributos. Dentre os doces 1, 2, 3 e 5 não se observou diferença significativa em todos os atributos avaliados, evidenciando um comportamento similar de tais formulações ao processamento.

Pela análise dos histogramas (Figura 4), verifica-se que para os atributos aparência e aroma a maior frequência de notas entre a escala (6 - gostei ligeiramente a 9 - gostei extremamente) foi atribuída ao doce 5. Para os atributos sabor e impressão global em relação à mesma escala, a maior frequência de notas foi atribuída ao doce 2. Nos atributos cor e textura, os doces 2 e 5 obtiveram a maior frequência de notas de ( 6 a 9) igual a $90 \%$. O doce 4 apresentou maior frequência de notas entre a 
escala ( 1 - desgostei extremamente a 4 - gostei ligeiramente), em todos os atributos avaliados, sendo o menos aceito pelos provadores.

Godoy et al. (2005) avaliaram sensorialmente compotas elaboradas com diferentes albedos cítricos. A média de todos os atributos avaliados situou-se na faixa entre 3,0 e 4,1 (desgostei ligeiramente e gostei ligeiramente). Os autores atribuíram a

Tabela 6. Valores das médias dos atributos sensoriais.

\begin{tabular}{ccccccc}
\hline Doces & Aparência & Aroma & Textura & Cor & Sabor & $\begin{array}{c}\text { Impressão } \\
\text { global }\end{array}$ \\
\hline 1 & $7,03^{\mathrm{a}}$ & $6,66^{\mathrm{ab}}$ & $7,00^{\mathrm{a}}$ & $7,33^{\mathrm{a}}$ & $6,43^{\mathrm{a}}$ & $6,53^{\mathrm{ab}}$ \\
2 & $6,90^{\mathrm{a}}$ & $7,03^{\mathrm{ab}}$ & $7,36^{\mathrm{a}}$ & $7,23^{\mathrm{a}}$ & $6,86^{\mathrm{a}}$ & $6,83^{\mathrm{a}}$ \\
3 & $6,60^{\mathrm{ab}}$ & $6,96^{\mathrm{ab}}$ & $6,60^{\mathrm{ab}}$ & $6,43^{\mathrm{ab}}$ & $6,40^{\mathrm{a}}$ & $5,56^{\mathrm{ab}}$ \\
4 & $5,76^{\mathrm{b}}$ & $6,20^{\mathrm{b}}$ & $5,73^{\mathrm{b}}$ & $5,53^{\mathrm{b}}$ & $5,80^{\mathrm{a}}$ & $5,63^{\mathrm{b}}$ \\
5 & $7,40^{\mathrm{a}}$ & $7,46^{\mathrm{a}}$ & $7,40^{\mathrm{a}}$ & $7,13^{\mathrm{a}}$ & $6,93^{\mathrm{a}}$ & $7,06^{\mathrm{a}}$ \\
$\mathrm{CV}$ & 23,03 & 20,98 & 25,05 & 25,53 & 26,69 & 24,54 \\
\hline
\end{tabular}

$\mathrm{CV}$ = coeficiente de variação; e médias seguidas pela mesma letra, nas colunas, não diferem estatisticamente entre si, pelo teste de Tukey a $5 \%$ de probabilidade.
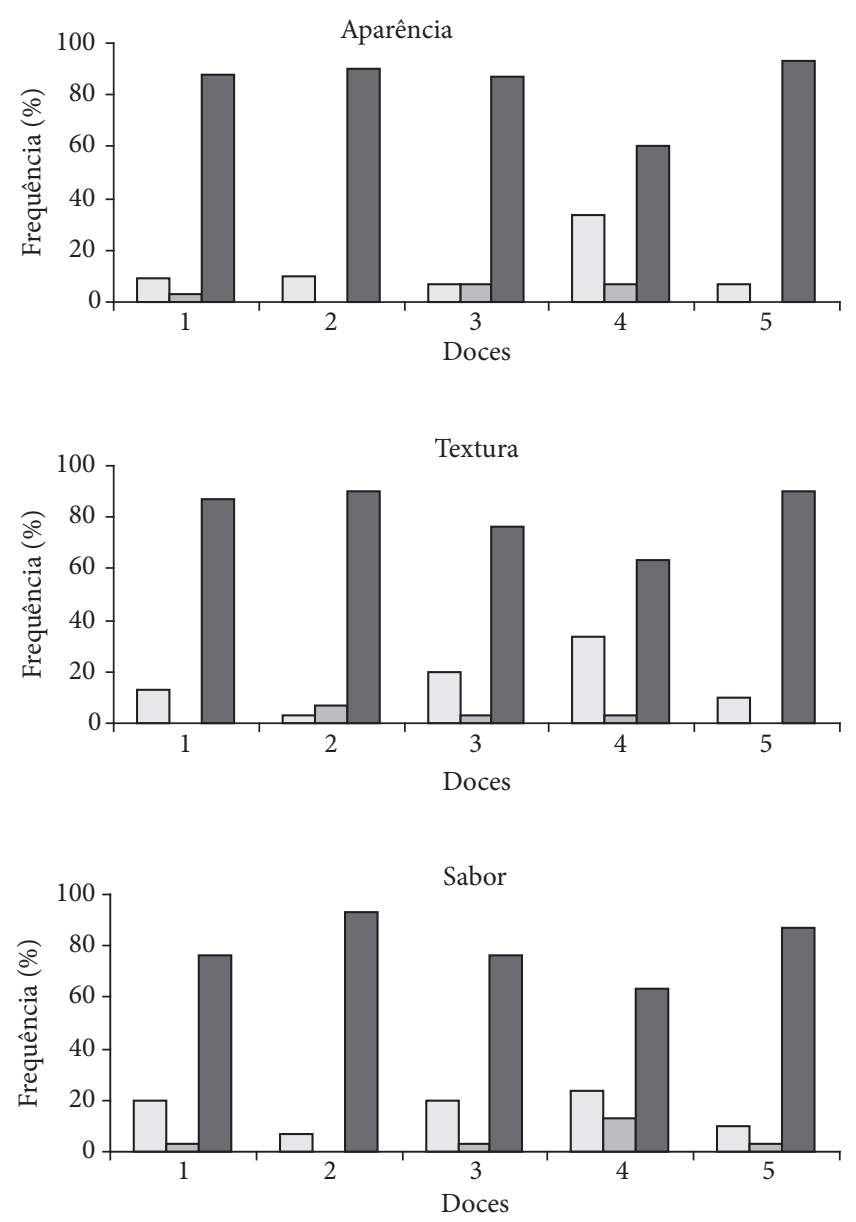

baixa aceitação das compotas de albedos cítricos ao fato da oferta desses produtos não ser comum na região em que o teste foi aplicado.

Com relação à intenção de compra do doce do albedo do maracujá em calda (Figura 5), 23,3\% dos provadores assinalaram que certamente comprariam e $40 \%$ assinalaram que possivelmente comprariam o doce 5 , se o encontrassem no mercado, sendo desta forma o doce com maior intenção de compra. Em relação ao doce 4, 20\% dos provadores assinalaram que certamente não o comprariam, obtendo menor intenção de compra pelos provadores.

Freitas e Jerônimo (2005) avaliaram a aceitação sensorial de doce de tomate em calda e a intenção de compra mediante equipe com 50 julgadores, utilizando escala hedônica estruturada. $\mathrm{O}$ doce de tomate em calda obteve grau de aceitação elevado com médias próximas a 8,0 , sendo que $77,6 \%$ dos julgadores possivelmente ou certamente comprariam o produto caso o encontrassem no mercado.
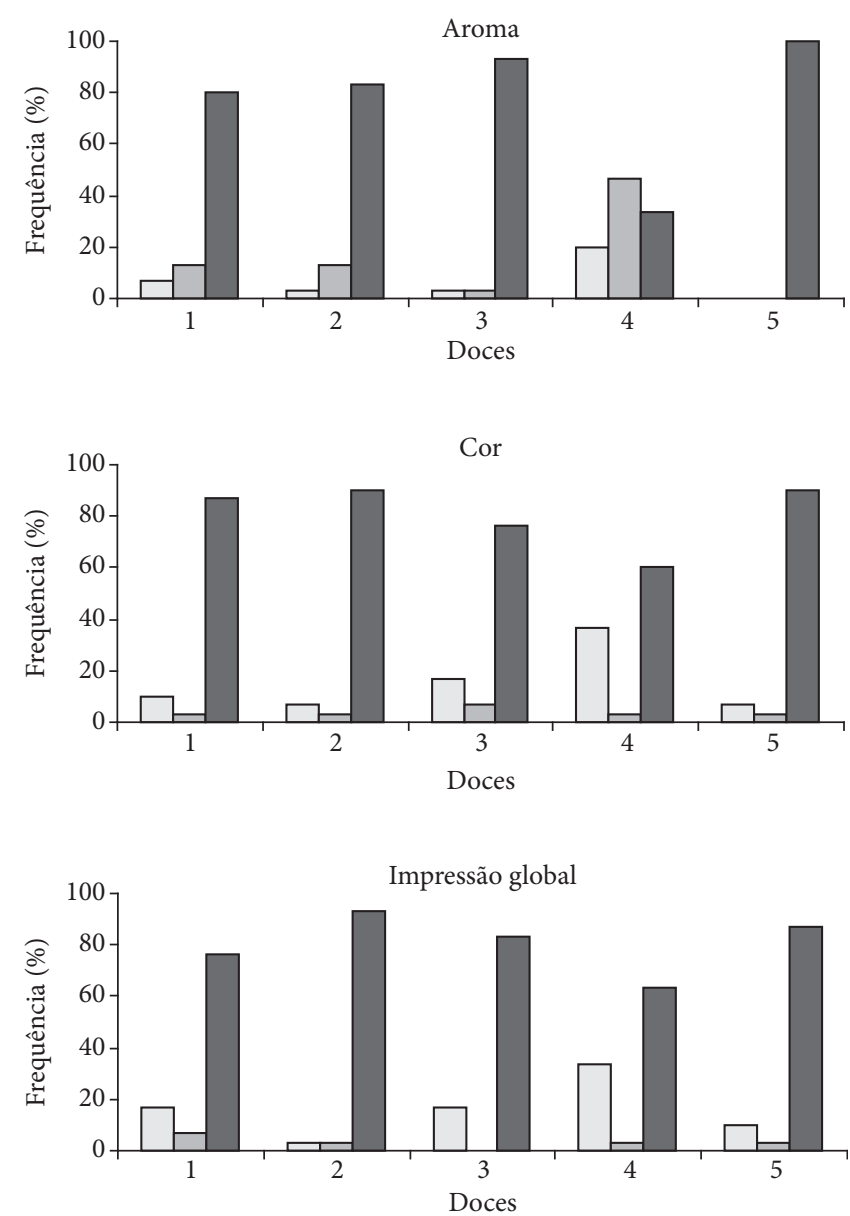

Notas de 1 a $4 \quad \square$ Notas $5 \quad \square$ Notas de 6 a 9

Figura 4. Histograma de frequência das notas atribuídas à aceitação dos atributos sensoriais de doces em calda do albedo do maracujá. 


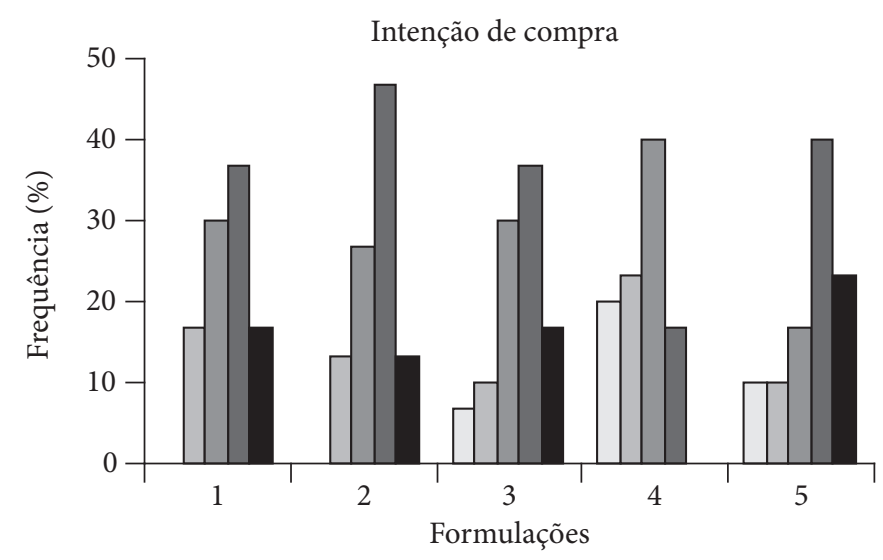

$\square$ Certamente não compraria

$\square$ Possivelmente não compraria

$\square$ Talvez comprasse, talvez não comprasse

$\square$ Possivelmente compraria

- Certamente compraria

Figura 5. Histograma de frequência dos valores atribuídos à intenção de compra de doces em calda do albedo do maracujá.

\section{Conclusões}

Os parâmetros do processo: volume de suco de maracujá empregado e tempo de cozimento dos albedos na calda, envolvidos no processamento dos doces do albedo do maracujá em calda, influenciaram significativamente as análises físicoquímicas de $\mathrm{pH}$ e sólidos solúveis para o albedo e de $\mathrm{pH}$ para a calda. Valores mais baixos de $\mathrm{pH}$ foram alcançados em volumes de suco e tempo de cozimento mais altos, tanto para o albedo como para a calda do doce. Maiores valores de SS no albedo foram encontrados em tempos de cozimento altos e em menores volumes de suco empregado.

A avaliação sensorial mostrou que os doces 1, 2, 3 e 5 não diferiram entre si estatisticamente quanto aos atributos analisados, apresentando elevada aceitação por parte dos provadores, enquanto o doce 4 foi o menos aceito e a corresponde intenção de compra foi maior para o doce 5 e menor para o doce 4.

Estes resultados indicam como condições adequadas, ao processamento do albedo de maracujá em calda, tempo de cozimento superior a 10 minutos e concentração mais elevada de suco de maracujá.

\section{Agradecimentos}

À FAPEMIG pelo apoio financeiro e à FRUTILAVRAS pela parceria neste projeto.

\section{Referências bibliográficas}

ASSOCIATION OF OFFICIAL ANALYTICAL CHEMISTS - AOAC. Official methods of analysis. $15 \mathrm{ed}$. Arlington, 2000.

BARROS NETO, B.; SCARMÍNIO, I. S.; BRUNS, R. E. Planejamento e otimização de experimentos. Campinas: UNICAMP, 1995. 299 p.
BRIGNANI NETO, F. Produção integrada de maracujá. Biológico, v. 64, n. 2, p. 195-197, jul./dez. 2002.

CÓRDOVA, K. R. V. et al. Características físico-químicas da casca do maracujá amarelo (Passiflora edulis Flavicarpa Degener) obtida por secagem. Boletim Centro de Pesquisa de Processamento de Alimentos, v. 23, n. 2, p. 221-230, 2005.

FERREIRA, D. F. Análises estatísticas por meio do Sisvar para Windows versão 4.0. In: REUNIÃO ANUAL DA REGIÃO BRASILEIRA DA SOCIEDADE INTERNACIONAL DE BIOMETRIA, 45, 2000, São Carlos. Anais... São Carlos: UFSCAR, 2000. p. 255-258.

FIGUEIREDO, L. P. et al. Determinação do tempo de equilíbrio para acidez e concentração de caldas de doce de casca de maracujá em calda. Higiene Alimentar, v. 21, n. 1, p. 63-64, 2007

FREITAS, D. G. C.; JERONIMO, E. M. Elaboração e aceitação sensorial de doce de tomate em calda. Boletim Centro de Pesquisa de Processamento de Alimentos, v. 23, n. 1, p. 37-46, 2005.

GODOY, R. C. B. et al. Estudo de compotas e doces cristalizados elaborados com diferentes albedos cítricos. Boletim Centro de Pesquisa de Processamento de Alimentos, v. 23, n. 1, p. 95-108, 2005.

GOMES, A. T.; CEREDA, M. P.; VILPOUX, O. Desidratação osmótica: uma tecnologia de baixo custo para o desenvolvimento da agricultura familiar. Revista Brasileira de Gestão e Desenvolvimento Regional, v. 3, n. 3, p. 212-226, 2007.

GONDIM, J. A. M. et al. Composição centesimal e de minerais em cascas de frutas. Ciência e Tecnologia de Alimentos, v. 25, n. 4, p. 825-827, 2005.

LIMA, J. R.; BRUNO, L. M. Estabilidade de melão processado por desidratação osmótica seguida de fritura. Ciência e Agrotecnologia, v. 30, n. 5, p. 937-941, 2006.

MACHADO, S. S. et al. Caracterização física e físico-química de frutos de maracujá amarelo provenientes da região de Jaguaquara - Bahia. Magistra, v. 15, n. 2, p. 229-223, 2003.

MODESTA, R. C. D. et al. Desenvolvimento do perfil sensorial e avaliação sensorial/instrumental de suco de maracujá. Ciência e Tecnologia de Alimentos, v. 25, n. 2, p. 345-352, 2005.

MORAES, M. A. C. Métodos para a avaliação sensorial dos alimentos. 8 ed. Campinas: Editora da UNICAMP, 1993.

OLIVEIRA, L. F. et al. Aproveitamento alternativo da casca do maracujá-amarelo (Passiflora edulis f. Flavicarpa) para produção de doce em calda. Ciência e Tecnologia de Alimentos, v. 22, n. 3, p. 259-262, 2002.

PATRI, P.; NOGUEIRA, J. N.; DIAS, C. T. S. Avaliação de carambola (Averrhoa carambola L.) dos tipos doce e ácido para o processamento de fruta em calda. Boletim Centro de Pesquisa de Processamento de Alimentos, v. 20, n. 2, p. 221-246, 2002.

SANDI, D. et al. Correlação entre as características físico-químicas e sensoriais em suco de maracujá amarelo (Passiflora edulis var, flavicarpa) durante o armazenamento. Ciência e Tecnologia de Alimentos, v. 23, n. 3, p. 355-361, 2003.

SATO, A. C. K.; CUNHA, R. L. Avaliação da cor, textura e transferência de massa durante o processamento de goiabas em calda. Brazilian Journal Food Technology, v. 8, n. 2, p. 149-156, 2005.

SATO, A. C. K.; SANJINEZ-ARGANDONA, E. J.; CUNHA, R. L. Avaliação das propriedades físicas, químicas e sensorial de preferência de goiabas em calda industrializadas. Ciência e Tecnologia de Alimentos, v. 24, n. 4, p. 550-555, 2004.

SOARES JUNIOR, A. M.; MAIA, A. B. R. A.; NELSON, D. L. Estudo do efeito de algumas variáveis de fabricação no perfil texturométrico do doce de manga. Ciência e Tecnologia de Alimentos, v. 23, n. 1, p. 76-80, 2003.

TONON, R. V.; BARONI, A. F.; HUBINGER, M. D. Estudo da desidratação osmótica de tomate em soluções ternárias pela metodologia de superfície de resposta. Ciência e Tecnologia de Alimentos, v. 26, n. 3, p. 715-723, 2006. 